\title{
FALSEAMIENTO \\ DE LOS PRINCIPIOS LIBERALES EN LA LEGISLACIÓN \\ DEL SEXENIO REVOLUCIONARIO
}

\author{
CARMEN BOLAÑOS MEJÍAS \\ Departamento de H. ${ }^{\mathrm{a}}$ del Derecho y de las Instituciones
}

Facultad de Derecho-UNED 


\section{SUMARIO}

Introducción. La esencia liberal del Sexenio. 1. Los límites al sufragio univerSal igualitario. 2. Asunción de funciones Judiciales por el Poder ejecutivo. 3. Quiebra del derecho de igualdad. Privilegios originados en la capacidad ecoNómicA. 3.1. La redención del servicio de armas. 3.2. Vigencia de la esclavitud. CONCLUSIONES. 


\title{
FALSEAMIENTO \\ DE LOS PRINCIPIOS LIBERALES EN LA LEGISLACIÓN \\ DEL SEXENIO REVOLUCIONARIO
}

POR

\author{
CARMEN BOLAÑOS MEJÍAS \\ Departamento de H. ${ }^{\text {a }}$ del Derecho y de las Instituciones
}

Facultad de Derecho-UNED

Resumen: Reflexión sobre cuatro aspectos concretos indicativos de la discutible coherencia con que se implantaron los principios liberales en las leyes fundamentales del Sexenio Democrático como punto de partida para fijar la nueva organización social y jurídica, aspiración frente a la cual se situaron una serie de hechos contradictorios. Como el sufragio universal, que se vio limitado en el caso de las mujeres, de los menores de veinticinco años y de quienes vivían en las posesiones de ultramar. La exacta división de poderes se falseó al retener el ejecutivo para sí la jurisdicción militar. E incluso se mantuvieron privilegios a partir del nivel económico de las personas. Fue el caso de la liberación mediante pago del servicio militar e incluso del mantenimiento de la esclavitud en las Antillas bajo la disculpa de no poderse revisar el derecho a la propiedad. 


\section{INTRODUCCIÓN. LA ESENCIA LIBERAL DEL SEXENIO}

Cuando se trata de calificar de forma panorámica los hechos subsiguientes a la Revolución de Septiembre de 1868 conviene matizar el término Sexenio Democrático. Si nos inclinamos a utilizar esta denominación en preferencia a otros posibles sinónimos es para reconocer la impronta ideológica que inyectó el liberalismo doctrinario a este período de la historia española del siglo XIX. Ahora bien, conviene precisar con rigor el alcance de esta acepción para desligarla de las connotaciones no deseadas a que la conduce la conceptualización tradicional. Resulta común que cuando se habla de Sexenio Democrático se quiera resaltar simplemente que se trata de un momento diferente a su precedente histórico inmediato, el reinado de Isabel II. Pero en realidad, esta caracterización considera sólo unas formalidades externas, por lo que peca de una simplificación excesiva. La búsqueda pertinente del significado preciso de la expresión Sexenio Democrático no se cumplirá hasta que alcancemos a integrar en ella los hechos concretos que demuestren se trató de una auténtica revolución liberal '

Los requisitos exigibles a un nuevo régimen respaldarían en el plano jurídico la implantación liberal desde estos condicionamientos: transformar el antiguo régimen personalizado en la monarquía absoluta en uno donde el poder proviniese de la igualdad entre los ciudadanos; sustituir la vieja estructura estamental por una organización social típicamente clasista ajena a los privilegios legislativos; y finalmente al-

1 Se sitúan en la línea de entender que la revolución septembrina tuvo repercusiones sociales, económicas y jurídicas suficientes para que el período que abría se calificase como democrático (aunque haya que aceptar que no alcanzaron la dimensión que prometían) los siguientes autores. JOVER ZaMORA, J.M. belina y el Sexenio Democrático, 3. ed., Madrid, Espasa Calpe, 1991 (Historia de España de Menéndez Pidal, v. 34). Prólogo; Bahamonde Magro, A., y Martínez, J.: Historia de España. Siglo XIX, Madrid, Cátedra, 1994; Jutglar I Bernaus, A.: Ideologías y clases en la España contemporánea, Madrid, Edicusa, 1968; López Cordón, M. a V.: La revolución de 1868 y la I República, Madrid, Siglo XIX, 1976; Artola GalLego, M.: EI modelo constitucional español del siglo XIX, Madrid, Fundación Juan March, 1979; FERNÁNDEZ SEGADO, F.: Las constituciones históricas españolas. Un análisis histórico-

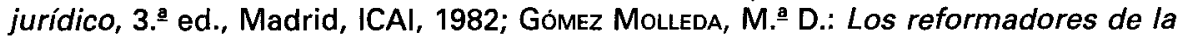
España contemporánea, Madrid, CSIC, 1981. También hay quien opina que precisamente el fracaso del Sexenio demuestra la ausencia de una estructura social adecuada. Es el caso de Carro Martinez, A.: La Constitución española de 1869, Madrid, Cultura Hispánica, 1952; EsteBAN, J.: Esquemas del constitucionalismo español, 1808-1976, Madrid, Universidad Complutense, 1976. 
canzar un nuevo sistema jurídico constitucional determinado por el propio pueblo y desarrollado mediante sus representantes legítimos. En este contexto, nos va a resultar más difícil detectar una línea coherente que permita comprobar si se asistió realmente entonces al inicio de una época verdaderamente democrática en el constitucionalismo español $^{2}$. En realidad, la Revolución de Septiembre, la monarquía democrática y la república que de ella se derivaron respondieron a unos intereses económicos muy concretos que aspiraban a consumarse de manera directa e inmediata a través del ensayo de un nuevo proceso político. Además, la limitación del tiempo en que estuvo vigente no favorece un análisis de las consecuencias que tuvo su implantación.

De cualquier forma, sería injusto reducir la actividad del Sexenio al proceso de desmantelamiento del sistema precedente, a pesar de que no podamos dotarle de unos perfiles políticos permanentes a lo largo de su transcurso, ya que en el fondo discurrió como un periodo abierto al progreso, que adoptó la doctrina liberal para revisar los fallos sociales de la democracia política. Desde este punto de vista hay que distinguirle a través de la firme presencia de un criterio, el que todo el derecho debía concebirse como un conjunto de normas vinculantes y derivadas de un texto fundamental. Bastaba que en las Cortes se votase un precepto legal, para que se entendiera que era obligatorio para todos los ciudadanos. La eficacia jurídica no podía discurrir fuera de los cauces de la voluntad popular expresada por mayoría. Esta idea caló de tal manera en la sociedad que así explica el hecho de que la revolución de 1868 diera principio a un período que se conocería como Sexenio Democrático ${ }^{3}$.

Dispuestos a establecer diferencias en cuanto al tratamiento y desarrollo de las ideas nos pusimos a reflexionar acerca de la mayor o

2 Véase Diez del Corral, L.: El liberalismo Doctrinario, 4." ed., Madrid, Centro de Estudios Constitucionales, 1984, págs. 457-665. Terrón, E.: Sociedad e ideología en los orígenes de la España contemporánea, Barcelona, Flamma, 1969, que desarrolla la idea de que toda asimilación exige unas condiciones previas, máxime si se trata de la adopción de instituciones sociales o jurídicas que permitan su encaje dentro de la cultura.

3 "Ahora bien: esa convicción creciente no supone, de inmediato, la aparición de un proletariado militante. Para llegar a esta última fase - la movilización del cuarto estado contra la burguesía - ha de producirse el paso de la noción de clase diferenciada a la de clase desprovista de instrumentos políticos o legales capaces de modificar el "status" ". Seco Serrano, C.: La toma de conciencia de la clase obrera y los partidos políticos de la era Isabelina, en LIDA, C. E., y ZAVALA, I. M. (Comp.).: La Revolución de 1868. Historia, pensamiento, literatura, New York, Publishing Company, 1968, págs. 25-74. 
menor plasmación de los principios más radicales del liberalismo en las supuestas libertades brindadas por la Revolución. Y encontramos que no es suficiente para nuestro objeto la mera relación de unas leyes - la ausencia de otras. Ya que no podemos dejar de abordar desde un estudio yuxtapuesto la disparidad que resulta de comparar lo proclamado y lo realmente aplicado. Resulta obvio admitir que las decisiones que entonces se activaron (leyes, reglamentos, actos de gobierno) estuvieran condicionadas poderosamente por interferencias originadas en pactos políticos o en grupos de presión, influencias todas que afectaron a la capacidad de tomar decisiones y de respaldarlas ${ }^{4}$. Sin duda determinaron también la oportunidad de que una norma fuese aplicada o de que quedase ausente. Asi pues, resulta inevitable relacionar estos datos con el carácter conflictivo del Sexenio. No podemos olvidar que en su transcurso se generarían alianzas y reagrupaciones de fuerzas reaccionarias que condicionaron la dinámica del conjunto y cuyo conocimiento es imprescindible para un estudio de aquella coyuntura.

\section{LOS LÍMITES AL SUFRAGIO UNIVERSAL IGUALITARIO}

La revolución de 1868 se inició con un pronunciamiento militar que perseguía implantar el liberalismo doctrinario. Al principio los efectos del alzamiento se concretaron geográficamente en la ciudad de Cádiz. La sociedad civil esperó para incorporarse al movimiento a que los militares se comprometieran públicamente a convocar Cortes Constituyentes. De esa manera, Prim tuvo que hacer una declaración expresa de los principios que se proponía establecer: primero, aplicar el sufragio universal y libre como fundamento de la legitimidad de todos los poderes del Estado; para después alcanzar otros propósitos buscando implantar cuantas libertades civiles y políticas se habían negado hasta entonces ${ }^{5}$. Todo ello en el contexto del principio básico que había de

4 Pérez Serrano, N.: Tratado de Derecho Político, 2. ${ }^{\underline{a}}$ ed., Madrid, Civitas, 1984; JimÉnez de PARGA Y CABRERA, M.: Los regímenes políticos contemporáneos, 5." ed., Madrid, Tecnos, 1974, y Varela Ortega, J.: Los amigos políticos. Partidos, elecciones y caciquismo en la Restauración. (1875-1900), Madrid, Alianza Universidad, 1977.

5 Boletín Extraordinario de la Provincia de Cádiz (20 de septiembre de 1868) y Boletín de la Revolución (Madrid, 25 de septiembre de 1868). La participación ciudadana también requirió de un manifiesto; se encargó de divulgarlo la Junta Revolucionaria de Sevilla, recogido de MAÑé y FlAQuer, J.: La revolución de 1868. Juzgada por sus autores, Barcelona, Jaime Jepús, 1876, pág. 85. 
inspirar las ideas jurídicas en el nuevo régimen político, el de igualdad de todos los ciudadanos ante la ley. De esta manera el ideario democrático llevaba a sus últimas consecuencias los principios del liberalismo.

No era suficiente con reconocer que se alcanzaban nuevas libertades. El gobierno provisional necesitaba legitimarse con el reconocimiento popular ${ }^{6}$. Por lo que hacía una "declaración de derechos», queriendo dar una efectividad inmediata a sus presupuestos ideológicos. Los derechos así reconocidos no dependían para su existencia de alguna norma que el gobierno pudiese desarrollar: "Como punto de partida para la promulgación de sus principios generadores... Todas las Juntas, expresión genuina de aquel movimiento, han proclamado los principios cardinales de nuestra nueva organización polítican'?. Aunque hablaba en plural, quería destacar de entre éstos al sufragio, que era considerado como derecho natural del pueblo. Lo que se corrobora al declarar que "la revolución ha establecido el sufragio universal como la demostración más evidente y palpable de la soberanía del pueblo". Mediante esta identificación explícita de la nación con la sociedad, el gobierno constataba que la soberanía nacional era un principio político incuestionable. No se precisaba de ningún texto fundamental para que los ciudadanos participasen de la dirección política, ya que la consideración de su necesidad se veía como algo consustancial al nuevo orden político. El propio gobierno reconocía que su legitimidad le venía concedida a través de esta clave jurídica, única desde la cual encontraba respaldo para sustituir un régimen por otro: "Convencido de la legitimidad de su poder, que se funda en el Manifiesto de Cádiz; en la investidura de la Junta de aquella ciudad que ha sido por segunda vez cuna de nuestras libertades; en el alzamiento sucesivo de todas las poblaciones de España; en el derecho y la consagración de la victoria; en el reconocimiento posterior de todas las Juntas que han funcionado en la Península; y finalmente, en la sanción popular".

La primera tarea emprendida por el Gobierno provisional fue la proyección técnica de su política democrática a través de la declaración

- Entendemos por legitimidad la coincidencia de valores de un grupo humano con los fundamentos políticos en que se basa el Poder. Con esta referencia se quería presentar al régimen como genuino representante de las aspiraciones sociales que la revolución reflejaba. La Junta Revolucionaria Central de Madrid había encargado a los generales Serrano, Prim y Topete la formación del gobierno provisional mediante Decreto publicado en la Gaceta de Madrid (4 de octubre de 1868).

7 Declaraciones del Gobierno Provisional a la Nación, publicadas en la Gaceta de Madrid (26 de octubre de 1868). 
de los principios liberales, razón por la cual sus decretos se ocuparon en forma casi exclusiva de incorporar al régimen jurídico las libertades proclamadas. El nuevo entramado legal se estrenó con el establecimiento del sufragio universal, en reconocimiento a su categoria de piedra angular del sistema. El Decreto de 9 de noviembre extendió este principio a las elecciones de Ayuntamientos, Diputaciones provinciales y Diputados a Cortes ${ }^{8}$. En la exposición de motivos el gobierno asumía el reto: "No desconoce ni esquiva la gran responsabilidad que echa sobre sí, al someter el principio del sufragio universal á un decreto, tan indispensable como deseado..., las grandes cuestiones que envuelve la confección de una ley electoral sobre el principio del sufragio universal, cuando de este han de nacer todas las instituciones del país". Asimismo se sentía obligado a frenar sus impulsos de no poner límite a su aplicación reconociendo que debía "restringir sus naturales deseos de dar al sufragio la mayor extensión posible, al fijar la edad». Vemos así cómo en el propio decreto de proclamación de la fe liberal el gobierno se autoimponía las primeras limitaciones a los principios revolucionarios. En el artículo primero reconocía que los españoles, para ser electores, debían estar inscritos en el padrón de vecindad que se formaría conforme a los artículos quince, dieciséis y diecisiete de la ley municipal ${ }^{9}$. Este artículo planteó problemas de interpretación que debió subsanar el ministro de la Gobernación con la circular de 17 de noviembre de 1868, emitida con el fin de explicar su correcto sentido. Esta aclaración fue necesario hacerla para evitar que las autoridades locales siguiesen aprovechándose de la Ley municipal para interpretar restrictivamente lo que pretendía el gobierno. Se había vuelto común excluir del padrón a todos los que no estuvieran inscritos en el término municipal como cabezas de familia, lo que impedía el ejercicio del derecho de sufragio a los mayores de edad por el mero hecho de formar parte de una unidad familiar ya constituida.

8 El ministro de la Gobernación decretaba el establecimiento del sufragio universal y la forma en que han de hacerse las elecciones de Ayuntamientos, Diputaciones Provinciales y Diputados a Cortes, recogido de Colección Legislativa de España, Madrid, Ministerio de Gracia y Justicia, 1868, v. 100, pág. 578.

9 La ley municipal que se puso en vigor el 21 de octubre había sido publicada por las Cortes constituyentes del bienio de 1854 a 1856. Los artículos 15, 16 y 17 se refieren a actualización y rectificación del censo; más importancia tenía el contenido del artículo 8, que disponía: «Es vecino de un pueblo todo español cabeza de familia que se halle inscrito en el padrón de vecindad del distrito municipal", Anuario administrativo y estadistico de la provincia de Madrid para el año de 1868. Reedición de la Consejería de Hacienda, Madrid, Instituto de Estadística de la Comunidad de Madrid, 1995, págs. 661-694. 
Otra limitación aceptada por el gobierno tuvo que ver con la restricción derivada de la edad de los votantes: "Son electores todos los españoles mayores de veinticinco años». Esta expresión se entendió en el sentido de que los varones eran el único colectivo que producía el efecto de identidad entre la nación y la sociedad. El gobierno lo justificó argumentando que se evitaban los peligros que suponía reconocer los derechos políticos a quienes la ley no concedia los civiles. Razonamiento que justificaba por extensión que dentro del concepto españoles no se contemplara el derecho de voto femenino, punto en el . que la mentalidad de la época fue unánime, puesto que este detalle no se consideró ni tan siquiera objeto de debate ${ }^{10}$.

El mismo silencio que se practicó frente al derecho de voto femenino se adoptó ante la publicación del Decreto de 14 de Diciembre. Lógicamente Ayala, ministro de Ultramar, utilizaba la misma táctica que el Gobierno Provisional. En la exposición de motivos alardeaba de los principios democráticos que inspiraban las tareas legislativas del gabinete al que pertenecia: "Una revolución que ha cambiado radicalmente todas nuestras condiciones políticas, [el gobierno provisional] no podía ni debía permanecer indiferente é inactivo ante este movimiento lógico e irresistible...»". Era menester, y venía impuesta por su

10 La extensión del sufragio universal se debatió durante toda la legislatura de las Constituyentes (1869-1871). Cánovas apuntaba la necesidad de limitar el sufragio $y$ recriminaba la incongruencia de universalidad que querían adjudicarle los liberales: "Y bien, señores: ¿es que no existe la mujer? ¿Es que no vive en ella la conciencia humana? Nadie lo duda ciertamente. Lo que hay es que, á pesar de lo que dice el proyecto de constitución, o más bien, de lo que quereis que diga, vosotros mismos reconocéis implícitamente al excluir de esta función á la mujer, que en el derecho electoral, hay y no puede menos de haber, fundamental y esencialmente, condiciones de capacidad. Suprimid estas diversas condiciones de capacidad, y tendreis que conceder de cualquier manera á la mujer el derecho electoral», en DSC 18 de abril de 1869), n. ${ }^{\circ} 44$, pág. 932 . Frente a este argumento propio de los moderados, se esgrimieron otros tratando de evitar nuevas limitaciones. A este propósito sirve la enmienda presentada por el republicano Garrido al art. $1 .^{\circ}$ del Título I de la Constitución de 1869, con el siguiente argumento: "El artículo dice "personas" y como los esclavos jurídicamente considerados no son personas, sino cosas, nosotros hemos temido que, interpretándolo de la misma manera los que vengan después á interpretarlo, creyeran que nosotros hemos querido conservar la esclavitud declarando que solo las personas son españoles, y que estas personas no son los que hoy son esclavos», en DSC (15 de abril de 1869), n. ${ }^{\circ} 50$, pág. 1074. Sobre la aplicación del sufragio universal en el Sexenio puede consultarse Martínez CuAdRADo, M.: Elecciones y partidos políticos de España (1868-1931), Madrid, Taurus, 1969, págs. 61-90; y ARToLA, M.: Partidos y programas políticos 1808-1936, Madrid, Alianza Editorial, 1991.

1 Decreto fijando los principios y reglas a que han de sujetarse las elecciones de Diputados a Cortes constituyentes en las provincias de Cuba y Puerto Rico. 
propia legitimación, la obligación de inspirarse en las nuevas doctrinas y anticiparse a lo que consideraba que ya era irreversible. Razón por la cual se reguló el sufragio universal para las islas de Cuba y Puerto Rico. Siempre bajo las especiales circunstancias que debian tenerse en cuenta para dichos territorios: "Las anomalías que presentan entre sí en aquellas islas las diversas divisiones territoriales, de las cuales sólo coinciden la económica, recientemente establecida...". Este decreto vino a concretar la Circular del 27 de octubre. El ministro había anticipa-do a los Gobernadores de ambas islas los objetivos y deseos del Gobierno respecto a dichas provincias. Esa misma circular anunciaba oficialmente los principios que inspirarían las nuevas relaciones con los territorios ultramarinos. Principios que no se podían entender como meras directrices cuando el propio ministro de Ultramar les aventuraba que, a raíz de la revolución, Puerto Rico y Cuba "gozarán las ventajas de la nueva situación e intervendrán con su inteligente criterio y con su voto en la resolución de las arduas cuestiones y sociales» ${ }^{12}$.

El ministro prometía agilidad para cumplimentar lo ya anunciado y anticipaba que se estaba estudiando en su ministerio la fórmula electoral que haría estas declaraciones realidad. No se podía aplicar la misma Ley electoral para todo el territorio español, pues debía considerarse la existencia de condiciones geográficas especiales así como de diversas situaciones en la estructura social. Por lo que no dudaba en añadir que "Dentro de los límites prácticos..., el Gobierno adoptará un sistema de elección tan amplio como sea posible..." para a continuación pasar a dar garantías a los propietarios de que ula revolución actual,... no aplicará a las Provincias de ultramar medida alguna violenta ni atropellará derechos adquiridos al amparo de las leyes...". Según el ministro, esta normativa se establecería bajo un criterio previsor y liberal. Pero la extensión de este derecho a las provincias ultramarinas ya adoptaba una forma incorrecta. Se publicaba un Decreto de aplicación exclusiva a dichos territorios. Era evidente que el gobierno optaba por mantener una legislación ajena a la que se aplicaba en el territorio peninsular a pesar de que a dichas provincias se las calificara de españolas.

Firmado por Adelardo López de Ayala, ministro de Ultramar, el 14 de diciembre de 1868 y publicado en la Gaceta de Madrid (20 de enero de 1869).

${ }_{12}$ "Circular del ministro de Ultramar indicando las reformas que, tanto en el orden político como en el social, piensa el Gobierno someter a la deliberación de la Asamblea constituyente, para que las islas de Cuba y Puerto Rico alcancen el grado de prosperidad y grandeza que merecen", recogido de Colección Legislativa de España, op. cit., págs. 496-499. 
En el decreto se fijaban también los principios y requisitos a que debian someterse las elecciones de Diputados a Cortes Constituyentes en las provincias de Cuba y Puerto Rico. $Y$ de nuevo surgieron diferencias al tomar la división económica como base de las circunscripciones. Lo que no hacía más que resaltar la importancia que tenía para el gobierno provisional la capacidad económica de los futuros electores. El gobierno había sido incapaz de hacer pública esta restricción en el cuerpo electoral peninsular, pues conocia la importancia que las Juntas revolucionarias habían dado a este principio. Pero no se privó de mantener dicha limitación en las colonias, lo que permitía entrever los intereses económicos que subyacían en el gobierno surgido de la revolución.

Detallaba el Decreto los requisitos exigidos para ser elector en aquellas circunscripciones. Como primera condición se exigía ser español y estar en pleno goce de todos los derechos. Para pasar a considerar de nuevo otra exigencia de índole económica que el ministro fue incapaz de obviar, al añadir la obligación de estar al corriente en el impuesto territorial, industrial o de comercio (art. $7 .^{\circ}, \mathrm{RD}$ de 14-12-1868). En consonancia con la especial diversidad social que el ministro reconocía en estos territorios, se tuvo en cuenta una incompatibilidad que no recogía la Ley electoral peninsular: «Tampoco podrán serlo [electores] los que en cualquier tiempo hayan sido condenados por delitos que castiga el decreto sobre represión del tráfico negrero" (art. 12, párr. $2^{\circ}, \mathrm{RD}$ de 14-12-1868). Lo que implicaba otra discriminación, pues dicha exclusión no afectaba a aquellos individuos que hubiesen cambiado su residencia y fuesen vecinos de cualquier ayuntamiento peninsular.

\section{ASUNCIÓN DE FUNCIONES JUDICIALES POR EL PODER EJECUTIVO}

La unidad de fueros había sido establecida por el ministro de Gracia y Justicia mediante el decreto de 6 de diciembre. En él se consideraba que lo "...necesario es que desaparezca por completo el fuero personal, civil y criminal de determinadas clases del Estado.... ${ }^{13}$. Se da-

13 Decreto de 5 de diciembre de 1868 estableciendo la unidad de fueros", recogido de Colección Legislativa de España, op. cit., pág. 872. En la exposición de 
ba asi término a la jurisdicción especial mercantil y fiscal, pasando una y otra como civil y como administrativa, a los jueces ordinarios.

No obstante se mantenía el fuero militar, a pesar de que el propio ministro lo consideraba una discriminación favorable para este colectivo: "... Y si los militares y marinos gozan en ellos de fuero, es sólo por privilegio y consideración a su persona...». Pese a que pueda parecer una decisión muy rápida, estas medidas fueron tomadas por el gobierno con mucha cautela. Lo demuestra el que recurriese a aplicar los principios liberales por partes, y que lo hiciese a través de un Decreto Ley, evidenciando que se había decidido por la vía menos conflictiva. El decreto le permitia reformar puntos muy concretos, habilitándole a la vez para mantener aspectos específicos de la organización foral militar. El Decreto de unificación de fueros redujo el ámbito de las competencias penales de la jurisdicción militar, también excluyó del conocimiento de los tribunales militares los negocios civiles y criminales de carácter común realizados por aforados de guerra y marina, sus familiares o su personal de servicio. Pero el gobierno mantuvo la existencia de esta jurisdicción y la utilizó en beneficio propio. Lo hizo utilizando la práctica política de declarar el estado de excepción, con la consiguiente implantación de la ley marcial. De esta manera la jurisdicción castrense se atribuía la competencia legal para determinados delitos ${ }^{14}$.

Así pues, la Ley de Orden Público aprobada el 20 de abril de 1870 (DSC, $n .^{\circ} 261$, ap. $2^{\circ}$ ) se preocupó más de establecer el marco de las excepciones que de fortalecer los preceptos constitucionales, revalidando un procedimiento de difícil encaje constitucional ${ }^{15}$. La ley dife-

motivos el ministro señaló las razones en que se fundamentaba, refiriéndose al art. 248 de la Constitución española de 1812: "En los negocios comunes, civiles y criminales, no habrá más que un solo fuero para todo clase de personas", y continúa: "La diversidad de fueros embaraza la administración de justicia...". De nuevo el gobierno deja entrever que el sentido de todas las reformas está en lo económico, por lo que declara que para los «negocios» no habrá más que un solo fuero. Nada dice respecto a cómo se habrán de resolver los conflictos ajenos a cualquier actividad lucrativa o mercantil.

${ }^{14}$ El gobierno provisional se propuso como máxima política el mantenimiento del orden. Era ésta una imposibilidad legal que los republicanos se encargaron de evidenciarla. Por lo que el gobierno utilizó la suspensión de garantías constitucionales ante la imposibilidad de reconciliar las premisas individualistas con las exigencias minimas del Estado. Véase CARR, R.: España 1808-1975, 3. ed., Barcelona, Ariel, 1985; PAYNE, S. G.: Ejército y Sociedad en la España Liberal, 18081936, Madrid, Akal, 1977.

${ }_{15}$ Sobre la utilización que el liberalismo español hizo del ejército para el mantenimiento del orden público, véase BALBÉ, M.: Orden público y militarismo en la España constitucional (1812-1983),. Madrid, Alianza Editorial, 1983. 
renció entre dos estados de suspensión, uno civil y otro militar, dependiendo de qué autoridades tomaran el mando de la situación. En su artículo doce disponía que si la autoridad civil era incapaz de controlar la situación, "lo prevendrá en un bando, que se publicará con la solemnidad posible, e inmediatamente dispondrá que la militar proceda a la adopción de las medidas que reclame la paz pública, previa la declaración del estado de guerra". Incluso este estado de guerra podía declararse por autoridades militares en el caso de una situación de urgencia, para lo cual se silenciaba oportunamente la exigencia constitucional de la ley previa. El artículo trece no hacía más que confirmar la preeminencia del orden militar estableciendo: "Si no hubiese acuerdo entre estas autoridades, ni tiempo para tomarlo, se entrará desde luego provisionalmente en el estado de guerra...». Para controlar dicho estado participaban las Fuerzas Armadas y la jurisdicción militar, aplicando otro orden penal, el correspondiente a la jurisdicción militar: "Los jefes principales de una rebelión o sedición armada, de carácter no militar, durante el período de guerra, quedan también sujetos al consejo de guerra ordinarion. Se autorizaba a las autoridades civiles $y$ militares para que establecieran en los bandos las penas en que incurrían los infractores.

El efecto principal no fue otro que permitir una sistemática intervención preventiva de derechos que la propia norma constitucional había desterrado: redadas, registros, detenciones, deportaciones y censura. Al no distinguirse entre estado de excepción civil y estado de guerra, las autoridades militares con la ayuda de simples bandos se hacían cargo de la situación. Mediante los bandos se llegó incluso a suprimir el principio de judicialidad, pues la ley tampoco hacía referencia explícita a la competencia de los jueces en tiempo de excepción.

De manera que no siempre se consiguió una legislación actualizada y conforme a los nuevos principios liberales. En definitiva la realidad política desplegó un mecanismo de defensa desde el pasado práctico que actuó como reductor de los principios consustanciales a la doctrina liberal. Actitud que se va a corresponder directa o indirectamente con el carácter divergente del Sexenio. 


\section{QUIEBRA DEL DERECHO DE IGUALDAD. PRIVILEGIOS ORIGINADOS EN LA CAPACIDAD ECONÓMICA}

\subsection{La redención del servicio de armas}

El gobierno, una vez realizado el cambio de régimen político, no creyó necesario seguir esforzándose por mantener el principio de igualdad entre todas las clases sociales con el mismo rigor que lo había proclamado ${ }^{16}$. El liberalismo había predicado la igualdad ante el Derecho como una censura contra los privilegios estamentales de la sociedad del Antiguo Régimen. Pero en el Sexenio no fue posible materializar la igualdad en el plano jurídico-político, lo que se tradujo en otro factor más de desestabilización del régimen democrático ${ }^{17}$.

Los principios liberales, que eran los que predominaban doctrinalmente, sirvieron para procurar la integración del servicio militar en el texto constitucional: "Todo español está obligado a defender la patria con las armas cuando sea llamado por la ley" (art. 28). Admitida la exigencia de un ejército permanente había que concretar en leyes actualizadas y conformes los principios reconocidos en la constitución ${ }^{18}$.

16 El temor de las autoridades a la reacción de las clases populares en los primeros momentos del Sexenio hizo que se llevara a cabo una campaña para evitar que el ayuntamiento madrileño se viera obligado a convocar a las quintas en medio de una gran tensión social. Para redimirles el ayuntamiento logró la colaboración de los mayores contribuyentes de la provincia. El principal suscritor, con 3.180 escudos, fue Juan Manuel de Manzanedo; pero entre otros suscritores destacaban el marqués de Novaliches (24), Conde de Reus (800), Duque de la Torre (1.000); los banqueros Weisweiller y Baüer (2.000), la Sociedad Española de Crédito Comercial (2.060) y el duque de Fernán Núñez (1.000). Las listas de suscriptores para la redención de los quintos correspondientes a Madrid capital en el año 1869 se publicaron durante el mes de septiembre. Para los suscritores mencionados véase el Boletín Oficial del Ayuntamiento (6, 20 y 23 de septiembre de 1869).

17 El Cohete, periódico republicano barcelonés, reclamaba prudencia a la hora de exigir los principios liberales: «... Harto saben los jornaleros, aunque se haya querido embrutecerles para mejor explotarles, que el más pequeño ataque a las personas o a las propiedades sería un arma poderosa en manos de los enemigos de la libertad..." (1 de octubre de 1868).

18 Fueron pocas voces las que se atrevieron a reclamarlo públicamente. Pero algunos lo hicieron por escrito y aportando posibles soluciones, como OLAVE y DiEz, S.: Bases para la reorganización del Ejército Español partiendo del supuesto de la abolición de las quintas. Proyecto dedicado á las Córtes de la Nación, Madrid, Novedades, 1871. Su proyecto concluía incorporando en la pág. 11 una premisa invariable: "No se admite redención ni sustitución. Toda la igualdad posible 
Pero el principio de igualdad jurídica de las personas, consustancial a la doctrina liberal, era incompatible con el sistema de reemplazos vigente en el que perduraba la redención en metálico. Esta posibilidad permitía al mozo sorteado pagarse un sustituto o bien librarse del servicio militar mediante una cantidad de dinero, opción que contó con la aprobación de quienes disponían de dinero para acogerse a ella, e incluso de la propia Hacienda que aceptaba con agrado los ingresos recibidos en concepto de redenciones.

\subsection{Vigencia de la esclavitud}

Durante el Sexenio todos los políticos iban a declararse en favor de la abolición de la esclavitud y en contra de la trata de esclavos, siguiendo razones éticas y morales que encarnaban el espíritu ideológico de la Europa revolucionaria del siglo $\mathrm{XIX}^{19}$. Pero lo cierto es que la cuestión abolicionista fue encarada en el Sexenio en contraposición con el derecho de propiedad privada ${ }^{20}$. Esta idea la defenderian los conservadores y moderados, considerando al esclavo como parte integrante de la hacienda por lo que, declarar la abolición de la esclavitud sin una indemnización adecuada era atentar contra el derecho de propiedad. Sus argumentos además de interesados no hacían más que poner de manifiesto las diferencias raciales que permitían a los blancos considerarse superiores a los negros. Romero Robledo expresó en las

ante el más honroso, pero también el más duro de todos los deberes que la patria tiene derecho á exigir de nosotros".

${ }_{19}$ "La estructura jurídica del sistema esclavista colonial español se basó en tres principios: la limitación de los derechos de los esclavos, la existencia de un régimen jurídico especial para las colonias y la aplicación de un abolicionismo gradual". Cfr. Alvarado Planas, J.: "Legislación penal y abolicionismo en Cuba y Puerto Rico. Siglo XIX»), en Revista de Derecho Penal y Criminología (UNED) (1993), n. ${ }^{\circ}$, págs. 111-151.

${ }^{20}$ Los españoles actuaron en consecuencia, tratando de retener las colonias que consideraban esenciales para mantener viva la idea de que España aún tenía un lugar entre las potencias europeas. Durante el siglo $x \mid x$ se contaba con los ingresos, en concepto de aduanas, que le permitía al gobierno español creer que conservaba una respetabilidad en el mercado internacional. Véase BAHAMONDE, A., y CAYUELA, J.: Hacer las Américas. Las elites coloniales españolas en el siglo Xix, Madrid, Alianza Editorial, 1992; y PIoueras Arenas, J. A.: La revolución democrática (1868-1874). Cuestión social, colonialismo y grupos de presión, Madrid, Ministerio de Trabajo y Seguridad Social, 1992, págs. 278-283 y 461 y ss. 
Cortes Constituyentes la opinión de la mayoría de los respetables políticos del Sexenio: "No vengo de ninguna manera á defender la esclavitud, que tiene mi condenación, como la tiene de todos los hombres ilustrados y cristianos... los propietarios de esclavos, amparándose en una legislación efectiva..., gozan una legítima propiedad...." ${ }^{21}$. La cuestión quedó planteada como una colisión de derechos que no se pudo resolver en favor del derecho de superior rango jurídico. Lógicamente, esta apreciación no estaba tan delimitada durante el Sexenio, pues el derecho a la propiedad para los reaccionarios será un derecho fundamental e ilegislable. Para el sector más radical de los republicanos la propiedad estaba basada en el trabajo y era reformable. Estas concepciones doctrinales tan difíciles de conciliar, hicieron que una propuesta tan natural y liberal como "abolir la esclavitud" fuera considerada como un ataque a la propiedad privada.

\section{CONCLUSIONES}

Sin duda hay que distinguir entre el alcance de los hechos y su significado en el sexenio 1868-1874. El Sexenio Democrático tuvo que adoptar en la práctica política unos comportamientos y una actitud que implicaban nuevas formas y maneras, imprescindibles para ejercer la democracia. Razón por la que se utilizó al pueblo para manifestar el descontento ante cualquier medida discutible.

En parecidos términos debemos considerar el impacto que significó para los políticos del momento aceptar la presencia de las minorías en el Parlamento. Toda la sociedad se vio obligada a reconocer que no sólo la aprobación de una constitución ponía en marcha el régimen político. La adopción de las ideas liberales en el texto fundamental creó una situación de crisis social que condicionó al gobierno a la hora de tomar sus decisiones. Su nueva legitimidad dependía del consenso mayoritario que le proporcionaran los tres partidos que participaron en la revolución. Pero éstos a su vez luchaban por defender la diversidad de tendencias y concepciones doctrinales que les caracterizaba, de ahí que se produjesen estas desviaciones legislativas. 
El mayor problema y el mayor éxito del sexenio se centraría en el reconocimiento de derecho al sufragio universal y en la implantación del derecho de asociación, lo que supuso concebir las relaciones entre el pueblo y el estado desde otros presupuestos jurídicos. El siguiente paso era concienciar al pueblo del valor que encerraban estos principios. Mientras pensaban esto disputaban entre sí en una serie de pruebas fallidas. En definitiva, los problemas del sexenio surgieron en el momento en que los principios dejaron de ser doctrina para concretarse en leyes actualizadas y conformes con el régimen democrático que se pretendía. 